BNL-77341-2007-CP

\title{
Multipacting Analysis of a Quarter Wave Choke Joint Used for Insertion of a Demountable Cathode into a SRF Photoinjector
}

\author{
A. Burrill, I. Ben-Zvi, BNL, USA; M. Cole, J. Rathke, AES, USA; \\ P. Kneisel, R. Manus, R. Rimmer, JLab, USA
}

Presented at the $22^{\text {nd }}$ Particle Accelerator Conference

Albuquerque, NM

June 25-29, 2007

June 2007

\author{
Collider-Accelerator Department \\ Brookhaven National Laboratory \\ P.O. Box 5000 \\ Upton, NY 11973-5000 \\ www.bnl.gov
}

Notice: This manuscript has been authored by employees of Brookhaven Science Associates, LLC under Contract No. DE-AC02-98CH10886 with the U.S. Department of Energy. The publisher by accepting the manuscript for publication acknowledges that the United States Government retains a non-exclusive, paid-up, irrevocable, world-wide license to publish or reproduce the published form of this manuscript, or allow others to do so, for United States Government purposes. 


\section{DISCLAIMER}

This report was prepared as an account of work sponsored by an agency of the United States Government. Neither the United States Government nor any agency thereof, nor any of their employees, nor any of their contractors, subcontractors, or their employees, makes any warranty, express or implied, or assumes any legal liability or responsibility for the accuracy, completeness, or any third party's use or the results of such use of any information, apparatus, product, or process disclosed, or represents that its use would not infringe privately owned rights. Reference herein to any specific commercial product, process, or service by trade name, trademark, manufacturer, or otherwise, does not necessarily constitute or imply its endorsement, recommendation, or favoring by the United States Government or any agency thereof or its contractors or subcontractors. The views and opinions of authors expressed herein do not necessarily state or reflect those of the United States Government or any agency thereof. 


\title{
MULTIPACTING ANALYSIS OF A QUARTER WAVE CHOKE JOINT USED FOR INSERTION OF A DEMOUNTABLE CATHODE INTO A SRF PHOTOINJECTOR*
}

\author{
A. Burrill\#, I. Ben-Zvi, BNL, Upton, NY 11974, U.S.A. M. Cole, J. Rathke, Advanced Energy \\ Systems, Medford, NY 11763, U.S.A. P. Kneisel, R. Manus, R. Rimmer, Jefferson Lab, Newport \\ News, VA 23606, U.S.A.
}

\begin{abstract}
The multipacting phenomena in accelerating structures and coaxial lines are well documented and methods of mitigating or suppressing it are understood. The multipacting that occurs in a quarter wave choke joint designed to mount a cathode insertion stalk into a superconducting RF photoinjector has been analyzed via calculations and experimental measurements and the effect of introducing multipacting suppression grooves into the structure is analyzed. Several alternative choke joint designs are analyzed and suggestions made regarding future choke joint development. Furthermore, the problems encountered in cleaning the choke joint surfaces, factors important in changes to the secondary electron yield, are discussed and evaluated. This design is being implemented on the BNL $1.3 \mathrm{GHz}$ photoinjector,[1] previously used for measurement of the quantum efficiency of bare $\mathrm{Nb}$, to allow for the introduction of other cathode materials for study, and to verify the design functions properly prior to constructing our $703 \mathrm{MHz}$ photoinjector with a similar choke joint design.
\end{abstract}

\section{Introduction}

The $1.3 \mathrm{GHz}$ photoinjectors have been used to study photoemission from the back surface of the injector, measuring the $\mathrm{QE}$ of niobium and comparing it to measurements made in a DC test stand. The results were good, and the effort has led to further $\mathrm{R} \& \mathrm{D}$ on $\mathrm{QE}$ measurements of other superconducting materials in $\mathrm{a} \mathrm{Nb}$ gun. After the initial testing we decided to modify one of our $1.3 \mathrm{GHz}$ guns to allow for the insertion of a demountable cathode stalk, a key technology needed for the $703 \mathrm{MHz}$ SRF photoinjector being designed and built for the BNL High Average Current Energy Recovery Linac project, and subsequent installation in the RHIC II electron cooling injector design. We began our analysis investigating the FZ Rossendorf design which has been successfully implemented for use with $\mathrm{Cs}_{2} \mathrm{Te}$ photocathodes.[2] Due to the need for active cooling of our cathode stalk, and for simplicity sake, a new design, the quarter wave choke joint, was chosen as it allows for implementation of active cooling more readily and presents itself as an easier design to engineer and build. Initial cold model experimental measurements were carried out by Tunnel Dust Inc. on three potential choke joint geometries, these were smooth parallel plates, rectangular grooved parallel plates and triangular grooved parallel plates. The cold model measurements showed that the triangular grooved plates provided the best multipacting suppression, processed the quickest and once stable did not degrade with time. After the cold model testing the SRF gun was modified to incorporate these triangular grooves, a challenge when working with niobium, and initial RF measurements were carried out. The results were not as expected, thus prompting this investigation.

\section{Initial Design}

The initial design of the choke joint was constructed based on the above mentioned cold model and simulations and the gun is shown in figure 1. The RF results of the cavity before being modified are shown in figure 2 , and from this graph one can see the excellent performance obtained.

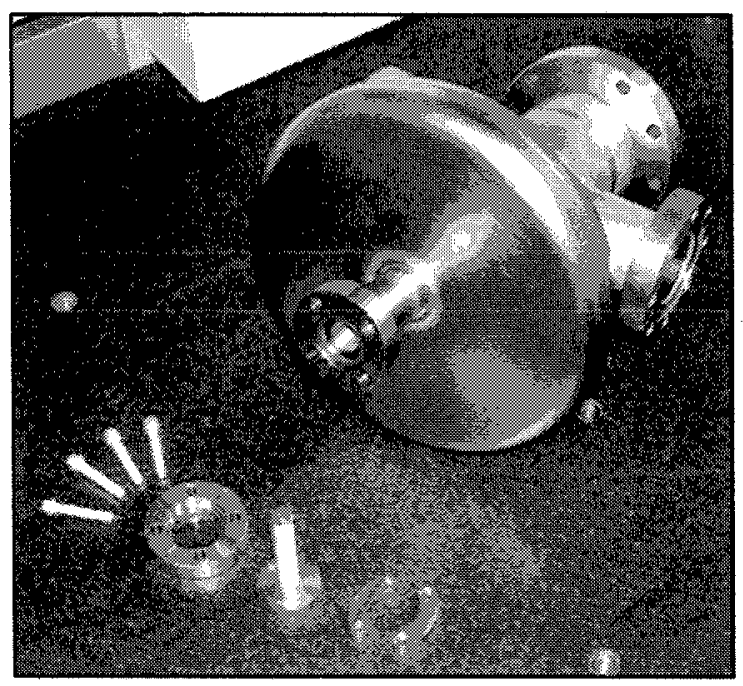

Figure 1. The $1.3 \mathrm{GHz}$ photoinjector with the cathode stalk.

After the choke joint was added the gun was again tested however the results were most discouraging. Figure 3 and 4 show the test results first with the cathode stalk removed, and then with it inserted. After evaluating the cavity performance, and the fact that there was a hard barrier at $2 \mathrm{MV} / \mathrm{m}$, it was realized that the multipacting 
suppression grooves which were meant to be cut in all choke joint surfaces, had in fact been left out of the outer coaxial section.

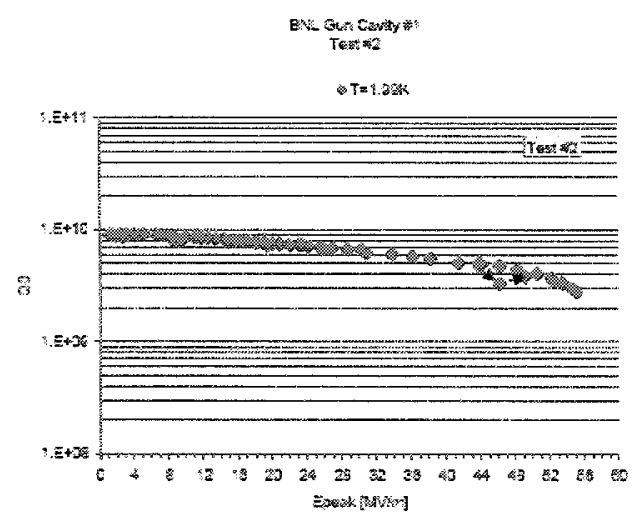

Figure 2. Initial cavity performance prior to the cavity modification, data collected by Peter Kneisel.

After this discovery it seemed fairly straight forward to install the grooves in the outer section, but before doing so this study was undertaken to better understand what had happened and what other methods might be available to mitigate it.

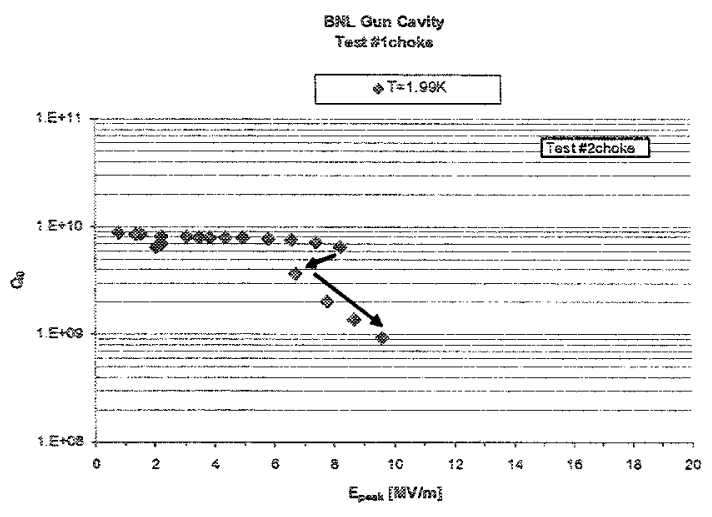

Figure 3. The performance of the cavity without the cathode stalk inserted.

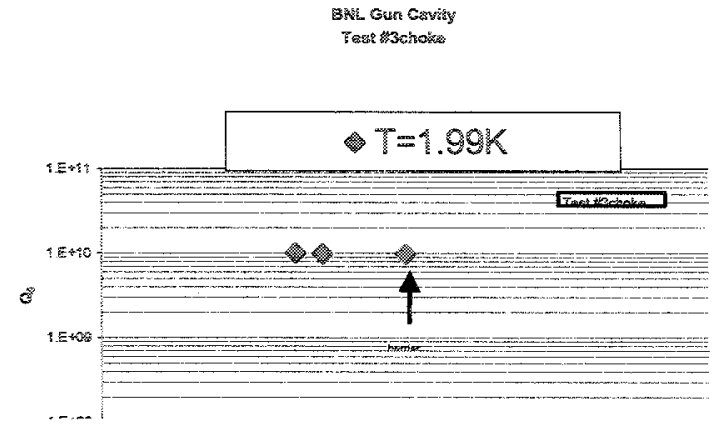

Figure 4. The performance of the original cavity with the cathode inserted

The multipacting code FISHPACT (courtesy of Genfa Wu, Fermilab) was implemented to study the choke joint design. [3,4] More details on the code can be found in references 3 and 4 , but in short the program is a multipurpose electron tracking code that was developed based on the Poisson/Superfish Field solvers.[5] The program allows the user to track the electron trajectories between impacts under varying accelerating gradient (Eacc), RF phases, and emission locations. The user can also change the secondary electron yield and initial electron energy.

The initial geometry of the choke joint, as shown in figure 5 was used as the input file and the program was run while varying a number of parameters to try and reproduce the experimental results while also studying the effect different parameters had on the outcome. In the end the multipacting analysis, shown in figure 6, was obtained which shows significant multipacting barrier over a very wide range of accelerating fields. One thing that was noted while using the program is how sensitive it is to the input geometry mesh, as one would expect. Any perturbation in the mesh can produce an area which appears to contain significant multipacting, but in truth may only be due to the mesh variation. This was a particular challenge for the choke joint as the grooves are very small, thus requiring a very fine mesh.

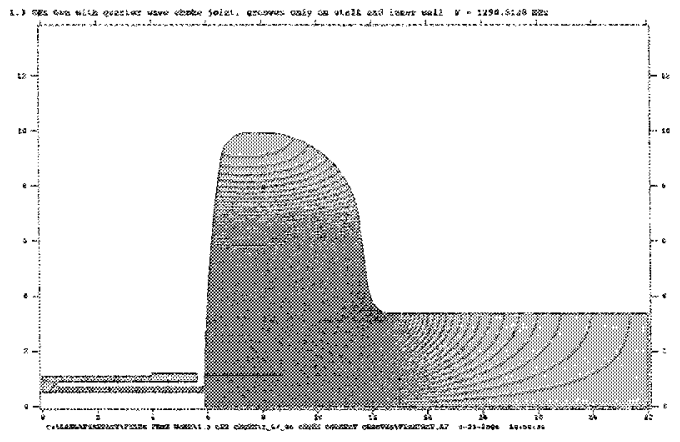

Figure 5. The original superfish file with the as built choke joint.

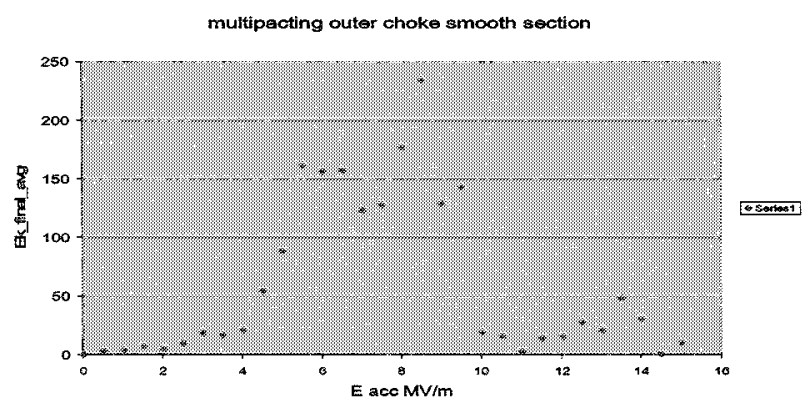

Figure 6. The multipacting analysis from the initial choke design.

\section{Choke Joint Modification}

Following the initial choke analysis several possible solutions were identified and analyzed. The most obvious was the grooves on all surfaces. This would require removal of the outer section of the choke joint, machining 
of the grooves and re-welding the assembly. Several less labor intensive solutions were also investigated. These included using a tapered outer coaxial section, thus removing the resonant condition required for multipacting, or simply enlarging the dimensions of the outer choke region. The analysis of several different geometries are shown in figures 7-9 below.

$3 \mathrm{~mm}$ gap, grooved both sides

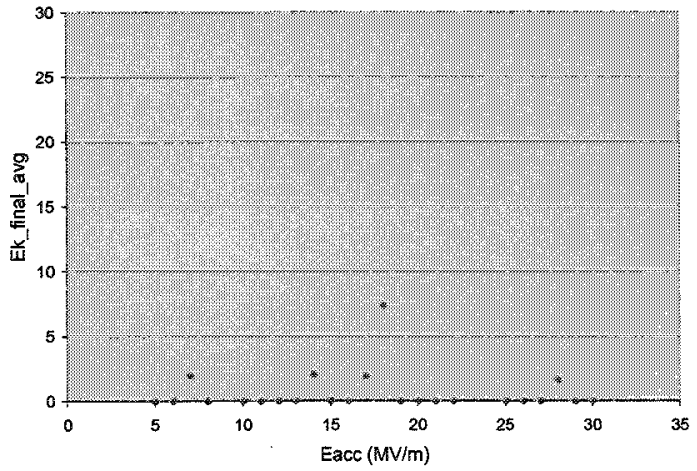

EE fros loter

Figure 7. The results of the multipacting simulation on the choke joint design with grooves on all faces.

Ek_final_avg

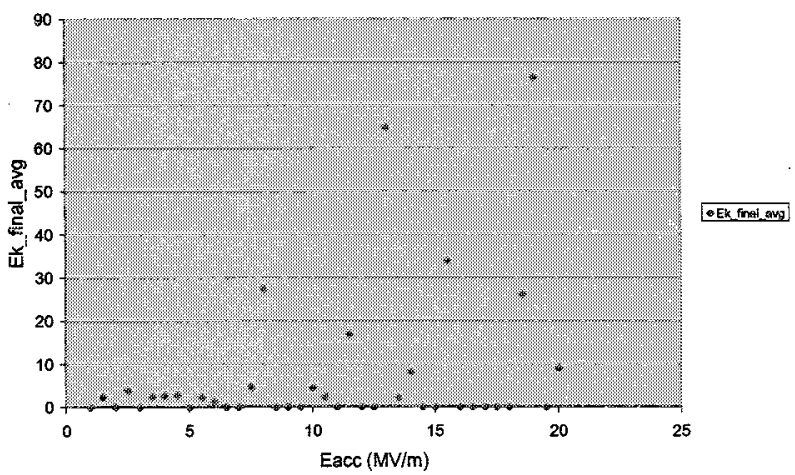

Figure 8. Multipacting analysis of the tapered outer choke section. The taper goes from $13 \mathrm{~mm}$ to $20 \mathrm{~mm}$ radius.

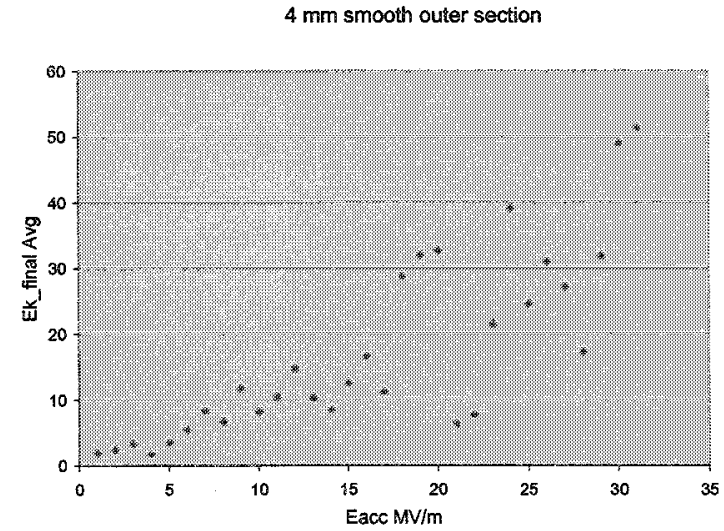

Figure 9. The multipacting analysis of a $4 \mathrm{~mm}$ wide outer choke joint that is smooth on both faces.

\section{Cavity Modification}

Following several months of analysis, boiled down to the graphs above, it was decided to go with the safe path and have the grooves installed on both sides of the outer choke joint. The dimension between the two adjacent walls was increased from 2 to $3 \mathrm{~mm}$ in the interest of making cleaning of the choke joint easier, thus improving our chances for success. The modification of the joint was a technical challenge due to the small dimensions and the 60 single point grooves that had to be cut in each face of the choke joint. The section was successfully machined and then e-beam welded back together. It then received a very thorough $\mathrm{BCP}$ cleaning and will be tested shortly, results of which will be published separately. The real challenge for a design like this is the ability to clean and assemble the structure such that one does not compromise the cavity performance and success of the project. Once this baseline design is proven, it will then be possible to begin analysis of different photocathode materials using this photoinjector, including such cathode materials as $\mathrm{CsK}_{2} \mathrm{Sb}$ and $\mathrm{GaAs}$, both of which have promising future applications to high average current ERLs.

\section{REFERENCES}

[1] M.Cole et al., "RF Design and Operating performance of the BNL/AES $1.3 \mathrm{GHz}$ single cell SRF gun," PAC'05, Knoxville, TN. p 3514, http://accelconf.web.cern.ch/AccelConfp05/PAPERS TPPE061.PDF

[2] D. Janssen et al., Nucl. Inst. and Meth. A 507 (2003) 314.

[3] http://www.jlab.org/ genfa/fishpact/

[4] E. Donoghue et al., "Studies of Electron Activities in SNS-type superconducting RF cavities," Proceedings to the 12th SRF Workshop, Cornell University, July $10,2005$.

hte://wwwl.jlab.org/U1/Publications/documents/AC F761.pdf

[5] Los Alamos Accelerator code Group, Poisson/Superfish Reference Manual, LA-UR-87-126 (1987). 